\title{
Como utilizar o cinema em sala de aula? Notas a respeito das prescrições para 0 ensino de História
}

\author{
Lara Rodrigues Pereira* \\ Cristiani Bereta da Silva $a^{* *}$
}

\section{Resumo}

Este artigo aborda a institucionalização de parâmetros voltados para a associação do cinema ao ensino de História. A análise foi realizada considerando o conjunto de documentos que tinham em comum discursos prescritivos relacionados ao uso de filmes em sala de aula. Nessa direção, foram analisados os Parâmetros Curriculares Nacionais (PCNs), duas coleções de livros didáticos e dois manuais, de épocas diferentes, direcionados aos professores de História. Buscou-se identificar rupturas e eventuais permanências, explorando-se aspectos constitutivos das prescrições de como deve-se usar o cinema em sala de aula. Essa discussão é recorte de pesquisa desenvolvida no Mestrado em História da Universidade do Estado de Santa Catarina (Udesc), defendido em 2013, que investigou como um grupo de professores de História que atua nos anos finais do ensino fundamental da rede municipal de Florianópolis usa filmes em suas aulas. As questões trazidas neste artigo pretendem contribuir para a compreensão das formas como as prescrições para o uso de filmes no ensino de História modificaram-se com o tempo e como são dadas no presente.

Palavras-chave: Ensino de História. Cinema. Prescrições.

\section{Introdução}

Por ter o poder de gerar símbolos junto ao público, o cinema foi utilizado por regimes totalitários como difusor de ideologias, e sua utilização no ensino já serviu a esses propósitos. Basta lembrar as narrativas construídas por Leni Riefenstahl sob encomenda do nacional-socialismo na Alemanha, dos filmes de Humberto Mauro produzidos pelo Instituto Nacional de Cinema Educativo (Ince) e dos filmes relacionados à Revolução Russa feitos por Eisenstein e subsidiados pelo Estado Soviético.

\footnotetext{
Recebido: 28/04/2014 - Aprovado: 22/06/2014

http://dx.doi.org/10.5335/rep.v21i2.4304
}

Mestre em História pela Universidade do Estado de Santa Catarina. Doutoranda no Programa de Pós-Graduação em Educação na Universidade Federal de Santa Catarina (UFSC). E-mail: lara-rod@bol.com.br.

** Professora do Departamento de História e dos Programas de Pós-Graduação em História e em Educação da Udesc. Bolsista produtividade do CNPq. E-mail: cristianibereta@gmail.com. 
As salas de aula não escapariam, tampouco, da importância decisiva do uso de imagens como ferramenta pedagógica. Dentre os meios, o cinema apareceria com a mais potente. No Brasil, a produção dos filmes educativos e a discussão que relacionaria cinema e ensino remontam às décadas de 1920 e 1930. Diferentes intelectuais identificados com o movimento da Escola Nova, como Fernando Azevedo, Francisco Campos, Afrânio Peixoto, Anísio Teixeira, entre outros, já apontavam o forte potencial do cinema na educação das crianças e jovens da época. As propostas integravam discursos relativos a mudanças significativas nos processos educacionais, privilegiando o aprendizado centrado nas atenções do aluno e incorporando, para a concretização desse processo, ferramentas auxiliares como imagens estáticas, mapas e filmes.

Desde então, a utilização do cinema como recurso para o ensino não representa nenhuma novidade, embora seus usos tenham sido, sensivelmente, revistos nos últimos anos. Isso deve-se ao fato de que, inicialmente, a linguagem cinematográfica era vista como apenas uma forma de ilustrar um evento ou paisagem, não era tomada como uma fonte capaz de produzir inúmeras problematizações a seu respeito.

Com o cinema é possível aprender História, e esse processo de cognição serve para interpretar a ação humana em tempos e lugares diferentes. Essas experiências impregnadas de tensões, rupturas e permanências modificam o modo como os sujeitos pensam de si mesmos, dos outros e do mundo em que vivem. Talvez, por esse motivo, o gênero épico faça tanto sucesso entre os/as fãs do cinema, pois o interesse por histórias é atravessado pela necessidade que os seres humanos têm de situar-se no tempo em que vivem. A consciência em relação à história, à temporalidade constitui "uma dimensão permanente da consciência humana, um componente inevitável das instituições, valores e outros padrões da sociedade humana" (HOBSBAWM, 1998, p. 98).

Filmes têm sido, cada vez mais, utilizados em sala de aula por professores de diversas disciplinas. A pesquisa a respeito de como sete professores de História da rede municipal de Florianópolis utilizam filmes em suas aulas indicou quão diversos podem ser esses usos e quão complexas são as relações estabelecidas entre as práticas e prescrições relativas ao uso de filmes nas aulas de História (PEREIRA, 2013). Neste artigo, a proposta é discutir como o cinema foi e é pensado como possibilidade de se ensinar História, por meio de prescrições formuladas em tempos distintos e em diferentes suportes. $\mathrm{O}$ exercício é menos comparativo e mais de compreensão de como as prescrições vêm sendo produzidas e veiculadas. 


\section{Como usar o cinema em sala de aula?}

Desde pelo menos a década de 1930, intelectuais do porte de Jonathas Serrano e Francisco Venâncio Filho preocuparam-se em orientar professores quanto ao uso do cinema em sala de aula. Para este artigo, escolheu-se discutir duas obras representativas dessas orientações, isto é, Como se ensina História, de Jonathas Serrano, publicado em 1935, e Como usar o cinema na sala de aula, de Marcos Napolitano, de 2003. Ressalte-se que essas foram escolhidas menos para destacar semelhanças ou diferenças e mais para pensar como o uso do cinema foi prescrito em dois contextos históricos distintos, em obras destinadas a um público específico, professores, em especial os de História.

Jonathas Serrano foi professor de História do tradicional Colégio Pedro II e respeitado por sua produção intelectual concernente à prática do ensino de História. Em 1931, esse professor já havia publicado o livro Cinema e Educação, em coautoria com Francisco Venâncio Filho, o que o credenciou na época como referência do tema, considerado, inclusive, para assumir o que seria o futuro Ince, fundado em 1937 (MORETTIN, 1995).

Marcos Napolitano, professor vinculado à USP, lançou, em 2003, o livro intitulado Como usar o cinema na sala de aula. No livro de Serrano, essa questão não é central, como em Napolitano, mas o autor a considerou importante o suficiente para dedicar-lhe um capítulo. A distância temporal existente entre uma obra e outra não lhes permite maiores aproximações teórico-metodológicas. Napolitano foi um pesquisador formado durante a década de 1980, quando a revolução documental já era realidade. Segundo Morettin, "A partir dos anos setenta, o cinema, elevado à categoria de 'novo objeto', é definitivamente incorporado ao fazer histórico, dentro dos domínios da chamada História Nova” (2003, p. 12).

O livro Como se ensina História, de Jonathas Serrano, foi lançado em 1935. Na apresentação da obra, Lourenço Filho escreve que o livro foi fruto de "ideias e da experiência do mestre que o compôs. É uma obra sentida e pensada e por isso mesmo de inestimável valor para nossos mestres" (LOURENÇO FILHO, 1935, p. 12).

No livro, há um capítulo específico a respeito de cinema no ensino de História, em que o autor debruça-se nas possibilidades desse novo recurso para a concretização da aprendizagem histórica. Escreve Serrano:

Não sou dos que se entusiasmam exageradamente com as possíveis aplicações do Cinema ao ensino da História. Parece-me que há certos equívocos na apreciação do assunto. Pelo que tenho observado, há muitos anos, os chamados filmes históricos não satisfazem as indeclináveis exigências de um verdadeiro filme educativo. Podem até, não raro, ser contraproducentes. Além de não servirem, pela grande metragem, a utilização propriamente escolar, são quase sempre inçados de anacronismos, de suposições infundadas, quando não de erros. Na melhor das hipóteses, são ensaios, mais ou menos aproximados, de reconstituições, de ambientes e tipos (1935, p. 112). 
De acordo com as observações de Serrano, os filmes comerciais que abordavam temas históricos poderiam ser contraproducentes, quando utilizados com o intuito didático, o que justificaria, a urgência da produção de filmes educativos, atendida com a criação do Ince, em 1937. Em sua análise reside o receio de comprometer o conteúdo a ser trabalhado na disciplina da História pelo uso de um filme que não foi concebido para ser educativo.

Serrano também aponta a preocupação com os anacronismos que ocorriam no cinema da década de 1930 e que, de certo modo, perduram até hoje. Não raro, pode-se observar anacronismos no cinema, ora evidentemente intencionais, como no filme "Maria Antonieta" (2007), da diretora Sofia Coppola (em que no armário da protagonista aparece um par de tênis), ora sutilmente intencionais, como no filme "Gladiador" (2000), de Ridley Scott, no qual o lugar reconhecido nos dias de hoje como Coliseu já era assim tratado no filme. Na época em que se passa a trama, o agora Coliseu se chamava anfiteatro Flávio.

Mas o anacronismo tão temido por Serrano não seria uma forma de transmitir outras mensagens que também podem ser trabalhadas em sala de aula? No caso do filme de Sofia Coppola, "O par de tênis" aparece para despertar no espectador a ideia de que aquela imperatriz imersa em riqueza, em poder e em luxo era também (além da figura séria apresentada nos livros didáticos de História) uma menina.

Já o anacronismo do filme de Scott é uma forma de fazer com que o espectador identifique o lugar em que ocorriam as batalhas, como aquele monumento em ruínas localizado no centro de Roma, que sempre aparece em documentários, filmes, telejornais e programas de televisão históricos ou contemporâneos. Afinal, como não chamar o Coliseu de Coliseu? Essa escolha, possivelmente, deu-se pelo fato de a leitura de Scott partir do presente e tencionar, localizar o espectador no passado, baseando-se na referência presente.

Pode-se considerar que os anacronismos em filmes funcionam como metáforas da História, e a rejeição de Serrano a isso advém, em parte, do fato de não conseguir reconhecer esses filmes como documentos de seu tempo.

A discussão que envolve o anacronismo no cinema e na escrita da História, por meio de romances ou textos acadêmicos, pode ser considerada, em certa medida inócua, pois sabe-se que é com base em escolhas do presente que se olha o passado. Em contrapartida, a desconfiança de Serrano com essas imprecisões tem legitimidade, pois como um aluno reagiria ao ver "o par de Converse" (o tênis que ele mesmo usa!) no armário de Maria Antonieta no filme que a professora passou em sala? Caso não houvesse o alerta prévio, esse poderia pensar que se trata de um erro de continuidade ou, então, ficar confuso. Qualquer das duas hipóteses comprometeria sua avaliação, não a respeito do período pré-Revolução Francesa, mas do documento que está estudando (o filme), pois nesse coexistem múltiplas temporalidades. 
O anacronismo também é apontado por Napolitano como uma armadilha a ser driblada pelo professor no trato com o cinema em sala de aula, o que aponta para certa permanência correlata ao tema, uma vez que também era uma preocupação de Serrano.

Este é um aspecto fundamental que o professor deve levar em conta e remete a uma armadilha a que o professor precisa estar atento: o anacronismo. Ocorre quando os valores do presente distorcem as interpretações do passado e são incompatíveis com a época representada. No filme histórico, ele pode decorrer não apenas da liberdade poética dos criadores do filme e das adaptações necessárias para que ele agrade ou atinja a determinado público, mas também do fato da representação do passado no cinema estar perpassada por questões contemporâneas ao momento histórico que produziu o filme. Respeitar e valorizar as abordagens plurais de um mesmo fato ou processo histórico não significa se eximir diante do anacronismo, muito comum em alguns filmes (NAPOLITANO, 2009, p. 38).

Uma questão destacada no texto de Serrano refere-se à dificuldade de se passar um filme inteiro em sala de aula, devido à falta de tempo. Este é um obstáculo que alguns professores estão conseguindo vencer atualmente, pois, com os recursos de edição de filmes popularizados, o professor pode recortar o trecho que quiser para utilizar em sala de aula sem ser surpreendido pela escassez de tempo. Mas, em 1935, essa não era a realidade, o domínio das técnicas de edição era restrito aos profissionais da área. Provavelmente, em razão dos limites de tempo das aulas, grande parte dos filmes produzidos pelo Ince era de curta-metragem, encaixando-os perfeitamente no tempo escolar.

Marc Ferro lançou, na década de 1970, o texto "O filme: uma contra-análise da sociedade?"- parte da obra História: novos objetos (1986). Este talvez seja o estudo mais importante no olhar historiográfico referente à produção cinematográfica, publicado cerca de quarenta anos depois da escrita de Serrano e cerca de trinta anos antes de Napolitano. Em decorrência disso, as abordagens distintas a respeito do mesmo objeto podem ser justificadas metodologicamente, pois Serrano era um pesquisador de documentos oficiais, haja visto seu clamor por um cinema legitimamente educativo, ao passo que Napolitano é filiado à ideia de que o documento é definido como tal segundo o olhar do pesquisador.

$\mathrm{Na}$ apresentação da obra de Napolitano, por meio da qual explicita suas intenções, há a delimitação de seu estudo para o uso de filmes comerciais em sala de aula e a exposição de uma máxima que norteará seu texto: todos os filmes, comerciais ou não, guardam em si possibilidades para o trabalho em sala de aula.

É importante lembrar que este livro irá se concentrar nas possibilidades de trabalho escolar com o cinema comercial (ficção ou documentário) e não nos vídeos educativos. Portanto, vamos analisar e discutir obras que não foram produzidas diretamente para o uso didático em sala de aula, mas para a fruição estética na sala de projeção. [...] Dos mais comerciais e descomprometidos aos mais sofisticados e "difíceis", os filmes têm sempre uma possibilidade para o trabalho escolar (NAPOLITANO, 2009, p. 11). 
Napolitano aponta para facilidades técnicas, impensáveis para Serrano, no trato com os filmes que proporcionaram sua ampla utilização em sala de aula, partindo do VHS até o DVD. Apesar de considerar o cinema comercial uma péssima influência para o saber histórico, Serrano via nesse um veículo de ideias, por meio do qual o indivíduo poderia aprender História, pois "as sensações da vista se gravam melhor na memória que as do ouvido" (1935, p. 111). Correlata a essa ideia está a teoria que envolve a consciência histórica, pois defende que os meios de comunicação de massa oferecem subsídios para formá-la.

Ultimamente a moda de romancear a história em livros tem provocado, no cinema, uma repercussão ainda mais lamentável. Deforma-se deliberadamente o passado, para efeitos românticos, ou cômicos, e o público aplaude e [...]. Desaprende o que sabia ou aprende errado para o resto da vida (SERRANO, 1935, p. 112).

Embora perceba nos filmes comerciais possíveis fomentadores do ensino, Serrano os desqualifica, apontando-os como deformadores da História e responsáveis por ensiná-la de maneira errada, sobretudo quando assistidos por não especialistas, conforme trecho recortado abaixo:

Para quem ama a História como ciência, esses filmes são irritantes. Para a maioria do público ignorante, são prejudiciais. Ao menos se todos os espectadores se dessem depois ao trabalho de estudar a verdade histórica sobre o episódio ou a personagem deformada na tela! Mas, nem há tempo nem elementos fáceis para a maioria. E as mensagens falsas perduram na memória (SERRANO, 1935, p 113).

Nessa passagem, ao indignar-se com a falta de verdade histórica veiculada pelo cinema, Serrano demonstra ser tributário de "uma história romântica como a de Michelet que primava pela ressurreição integral do passado ou pela história positivista de Ranke descrita como aquilo que realmente aconteceu" (LE GOFF, 2003, p. 13). Sua insatisfação é marcada pela crença na cientificidade de uma história-verdade não acessível para leigos, o que era compatível com o período em que viveu e escreveu.

Os paradigmas para o uso do cinema em sala de aula foram sensivelmente alterados com o tempo e, no Brasil, passaram a ser institucionalizados por meio dos Parâmetros Curriculares Nacionais - História (PCNs), publicados em 1998. Em resposta à determinação do art. 210 da Constituição Federal, os PCNs teriam a prerrogativa de fixar "conteúdos mínimos" com a finalidade de "assegurar formação básica comum e respeito aos valores culturais e artísticos”. A partir disso, pode-se perceber que o cinema, importante produto da indústria cultural, é parte integrante das preocupações com conteúdos e conceitos que darão origem aos PCNs. Em decorrência disso, percebe-se a valorização do uso de "diferentes fontes na consecução dos objetivos do ensino de História”. Nessa direção, o cinema aparece como importante fonte conforme trecho abaixo: 
No caso do trabalho didático com filmes que abordam temas históricos é comum a preocupação do professor em verificar se a reconstituição das vestimentas é ou não precisa, se os cenários são ou não fiéis, se os diálogos são ou não autênticos. Um filme abordando temas históricos ou de ficção pode ser trabalhado como documento, se o professor tiver a consciência de que as informações extraídas estão mais diretamente ligadas à época em que a película foi produzida do que à época que retrata. É preciso antes de tudo ter em mente que a fita está impregnada de valores, compreensões, visões de mundo, tentativas de explicação, de reconstituição, de recriação, de criação livre e artística, de inserção de cenários históricos construídos intencionalmente ou não por seus autores, diretores, produtores, pesquisadores, cenógrafos, etc. Para evidenciar o quanto os filmes estão impregnados de valores da época com base na qual foram produzidos tornam-se valiosas as situações em que o professor escolhe dois ou três filmes que retratem um mesmo período histórico e com os alunos estabeleça relações e distinções, se possuem divergências ou concordâncias no tratamento do tema, no modo como reconstitui os cenários, na escolha de abordagem, no destaque às classes oprimidas ou vencedoras, na glorificação ou não dos heróis nacionais, na defesa de ideias pacifistas ou fascistas, na inovação ou repetição para explicar o contexto histórico, etc. Todo o esforço do professor pode ser no sentido de mostrar que, à maneira do conhecimento histórico, o filme também é produzido, irradiando sentido e verdades plurais. São valiosas as situações em que os alunos podem estudar a história do cinema, a invenção e a história da técnica, como acontecia e acontece a aceitação do filme, as campanhas de divulgação, o filme como mercadoria, os diferentes estilos criados na história do cinema, a construção e recriação das estéticas cinematográficas etc (BRASIL, 1998, p. 88-89).

No início do texto não fica muito evidente a preocupação com a possível existência de anacronismos nos filmes históricos, conforme averiguado na escrita de Serrano e Napolitano. Há apenas a constatação de que o professor, normalmente, concentra-se nas características como nos figurinos, nos cenários e nas locações no intuito de identificar a falta de fidedignidade histórica presente nesses, e que, eventualmente, venha a comprometer o entendimento dos alunos referente ao período estudado.

Pode-se perceber que a possibilidade de um filme ser tratado apenas como ilustração e não como documento é contemplada pelos PCNs. O uso da palavra pode no lugar de deve abre espaço para que filmes (históricos ou não) sejam utilizados para o ensino da disciplina de História apenas com o intuito de ilustrar períodos, eventos e personagens, não necessariamente como fonte documental para análise de tais questões. Isso representa certa incongruência com outra recomendação existente nos próprios PCNs referente à atenção que o professor precisa dar a aspectos como concepção, produção, distribuição e recepção do fillme, características estas que ajudam a atribuir identidade ao documento.

Outro aspecto que se pode aferir com base nos PCNs, é que, nesse trecho específico, há o conselho, o método, enfim, há a prescrição de metodologia de trabalho que o professor poderá empregar quando resolver utilizar filmes em suas aulas. Isso fica evidente quando, no documento, há a posologia do uso de dois ou três filmes que tratem do mesmo período histórico, a fim de aprofundar as discussões. 
A indicação de trabalho voltada para a compreensão da história do cinema existente nos PCNs marca o reconhecimento dessa indústria do entretenimento como importante fonte de conhecimentos históricos. Mas, em sala de aula, em geral, essa História não vem contempleta, possivelmente pelo inchaço dos currículos, que precisam abarcar grandes períodos, deixando a história contemporânea resumida a poucas aulas.

A formação cultural dos sujeitos, de acordo com Palma Filho (1997, p. 18), é uma das preocupações dos PCNs, pois estes encaram o currículo como uma seleção de elementos constituintes de conceitos, procedimentos e atitudes inerentes à educação. Para tanto, podemos afirmar que o cuidado com indicações de temas e recursos tem por objetivo o desenvolvimento de certas habilidades, por parte dos educandos, que serão decisivas em sua formação escolar e social.

A institucionalização do uso do cinema para ensinar História em sala de aula, por meio dos PCNs, acaba por subscrevê-lo como recurso e conteúdo da disciplina. Contudo, nem sempre aparece assumindo essa dupla função nos materiais indicativos para seu uso (manuais ao professor e livros didáticos), o que pode representar certo prejuízo na sua incorporação e apropriação por parte da comunidade docente.

\section{Livros didáticos e os usos do cinema em sala de aula}

De acordo com Bittencourt (2004, p. 34), o livro didático é um objeto da cultura escrita bastante corriqueiro e familiar, mas de complexa definição. Isso ocorre, pois sua função será determinada pelo uso que será feito desse. Em razão disso, congrega o status de mercadoria e de veículo de conhecimento e ideias, tornando-o, mesmo quando pouco usado pelos professores, um importante meio de aquisição de conhecimento por parte dos alunos que a esse tem acesso.

A ampla distribuição de coleções didáticas, na rede pública de ensino brasileira, contribui para que os alunos de toda a educação básica tenham a possibilidade de um convívio intenso com esses livros, ocorrido não apenas no espaço escolar, mas também fora deste, pois, normalmente, podem levá-los para casa. Seu caráter de manual de instruções e sua popularidade junto a docentes e discentes ajudam a torná-lo possivelmente o mais importante material prescritivo no âmbito educacional.

Os livros didáticos selecionados para este artigo foram utilizados pelos professores entrevistados na pesquisa Entre prescrições e práticas: o cinema no ensino de História (PEREIRA, 2013). Os professores entrevistados referem-se aos livros didáticos como um apoio que continua fazendo parte de sua rotina, mas que está perdendo espaço frente a outros materiais de pesquisa incorporados a sua prática. Embora suas falas não demonstrem muito entusiasmo referente ao uso dos livros 
didáticos, todos escolheram uma coleção ou herdaram essa escolha. Seu trabalho, por mais que não seja diretamente baseado em tais livros, será permeado pelo uso, ao menos esporádico, desses.

As coleções analisadas aqui serão História Temática e Projeto Araribá História. Trata-se de séries de livros didáticos que fizeram parte da escolha realizada pelos professores da rede municipal de Florianópolis em 2010, os quais foram adotados por quatro dos sete professores entrevistados. Suas abordagens, no que diz respeito ao uso do cinema em sala de aula são bem diferentes, e tais diferenças serão expostas a seguir.

\section{Coleção História Temática}

A coleção História Temática, editada pela Scipione, assinada por Conceição Cabrini, Roberto Catelli Jr. e Andrea Montellato, apresenta a abordagem histórica focada em temas específicos como propriedade, terra, trabalho, etc. Sua estrutura básica é mantida ao longo dos capítulos, repetindo-se nos quatro volumes que compõem a coleção. Há, logo no início de cada um dos quatro livros, a estruturação dos capítulos, com o intuito de que o aluno e o professor inteirem-se a respeito das possíveis abordagens que serão dadas aos conteúdos, pesquisas e atividades propostas.

Nessa coleção, não há uma seção referente à indicação de filmes históricos, como podemos observar em outras coleções de livros didáticos, mas há, em contrapartida, uma latente preocupação com o uso de documentos em sala de aula. Prova disso é a existência das seções "Trabalhando com Documentos" e "Trabalhando com Documentos Visuais". Contudo, o tópico "Trabalhando com Documentos Visuais" refere-se geralmente a gravuras, quadros, obras de arte, revistas e jornais impressos, e dessa forma telejornais, novelas e filmes raramente são considerados nessa seção. No livro do oitavo ano da História Temática, há apenas uma referência ao cinema que aparece na página 126. Nesta há uma imagem de um dos cartazes de divulgação do filme Jeca Tatu (1959), estrelado por Mazzaropi e dirigido por Milton Amaral. A gravura aparece com o intuito de elucidar a questão colocada no corpo do texto referente à produção escrita de Monteiro Lobato, sobretudo na obra Urupês. Apesar da posição de destaque na página, não há menção a nenhuma atividade que pudesse ser feita baseada no filme de Mazzaropi. 


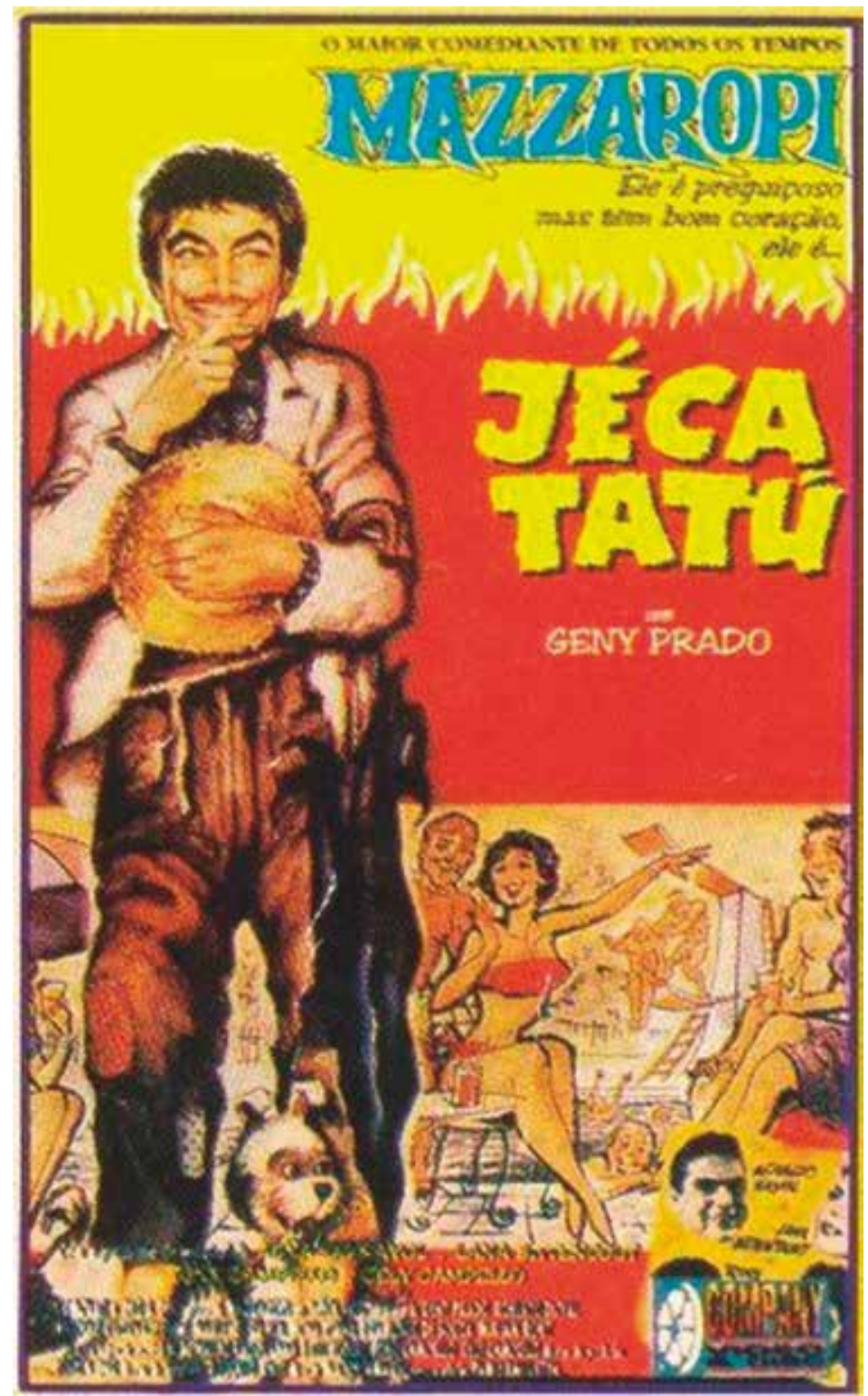

Cartaz de divulgação do filme Jeca Tatu, de $1959^{1}$

O personagem de Jeca Tatu foi criado por Lobato na primeira década do século XX, retratado em artigos que publicava no jornal O Estado de S. Paulo. Em 1918, o autor publicou o livro Urupês, cujo protagonista, baseado nesses artigos, era o Jeca Tatu. Sua obra ajuda a retratar questões importantes do Brasil daquele período, 
como a contraposição campo versus cidade e a caracterização (feita por um erudito como Lobato) do brasileiro do interior, sem instrução formal, acometido por mazelas variadas e sem assistência do Estado.

As diferenças na caracterização do Jeca, no filme estrelado por Mazzaropi, para o Jeca de Lobato são marcantes, pois, enquanto o autor evidenciava sua preguiça e apatia (nessa edição de Urupês), no filme percebe-se como característica do Jeca Tatu, além da preguiça, certa astúcia. Estas diferenças no retrato do personagem de sua criação até sua representação cinematográfica podem dizer muito a respeito do Brasil nesses dois períodos, o que faz do filme fonte riquíssima de trabalho em sala de aula. Mas tais questões não são abordadas no livro didático, pois o cartaz do filme vem apenas para ilustrar o texto escrito relacionado ao livro Urupês, e o fato de os protagonistas do livro e do filme serem Jecas diferentes, pela distância temporal que os separava, não é mencionado.

No volume do sétimo ano, há referência ao filme do personagem dos quadrinhos homem-aranha (2002). O cartaz de divulgação do terceiro filme da série, datado de 2007, ilustra uma reflexão a respeito do mito e memória histórica localizada no início do primeiro capítulo do livro. Após a ilustração do cartaz do homem-aranha, há também duas imagens extraídas de animações dos personagens batman e super-homem. As imagens são seguidas por uma atividade composta por cinco questões discursivas.

1) Você conhece essas imagens?

2) Quais são as características destes personagens?

3) Existe algo em comum entre eles?

4) Em sua opinião, o que significa ser um herói?

5) Quem você considera um herói? Por quê? (CABRINI et al., 2010, $7^{\circ}$ ano, p. 13).

A atividade proposta pelo livro considera as impressões dos alunos a respeito dos mitos, questionando se esses seriam, em linhas gerais, "uma forma de explicar a história de determinado povo ou evento". Após a apresentação dos mitos contemporâneos ocidentais, os personagens em quadrinhos, o livro traz representantes da mitologia grega e mitos fundadores de determinados segmentos da sociedade brasileira, como Padre Cícero e Zumbi dos Palmares. Nesse caso, assim como no caso do filme de Mazzaropi, o cartaz do filme é usado como ilustração da questão do mito. $\mathrm{O}$ livro leva em consideração o sucesso da franquia de filmes do Homem-Aranha entre os jovens para acionar suas memórias a respeito de como seria construído um mito.

O homem-aranha é um personagem essencialmente bom e que, devido a uma mutação promovida em laboratório, adquire superpoderes que utilizará para combater o mal, diferentemente, por exemplo, de deuses ou semideuses da mitologia 
grega que se tornam mitos a partir do momento de seu nascimento. Sem falar nos mitos "reais" abordados no livro, como Padre Cícero e Zumbi, alçados à categoria mítica devido à divulgação de seus feitos.

Nesse caso, mais uma vez o cinema é usado levando-se em conta as dimensões que tangenciam a memória de seus espectadores, uma vez que um filme tão famoso entre os jovens como o Homem-Aranha é capaz de produzir discussões a respeito da mitologia, pois está subentendido que já foi visto, se não por todos, pela maioria dos alunos de uma turma de sétimo ano.

No livro do nono ano, não aparece nenhuma referência a qualquer filme, seja histórico, documentário ou ficcional. Já no livro do sexto ano, aparece o maior número de inserções referentes a filmes da coleção História Temática. Na seção "Painel", há uma abordagem aos diferentes tipos de documentos históricos divididos em três categorias distintas: documentos escritos, documentos visuais e documentos orais. Cada tipo de documento é apresentado a partir de sua definição, seguida por exemplos. No caso dos documentos visuais a explicação apresentada no livro é:

[...] uma outra forma de o homem fazer registro de sua História é através de imagens. Podemos representar as ideias, os objetos, as pessoas e os acontecimentos por meio de figuras, desenhos, esculturas, pinturas ou fotografias. Existem formas de representação que unem a imagem e a escrita, como histórias em quadrinhos, e outras que unem a imagem e a fala, como filmes ou documentários (CABRINI et al., 2010, 6ํㅜano, p. 37).

No que diz respeito ao cinema, o livro, para além das explicações acerca do que seriam documentos visuais "falados", apresenta ainda cenas de filmes muito conhecidos do público em geral que transpassam a História de maneiras diferentes. Ao tratar de arqueologia, o filme chamado a falar do tema é Indiana Jones e o Reino da Caveira de Cristal (2008). Na trama Harrison Ford vive um arqueólogo, cujas aventuras em busca de artefatos raros acabam levando-o a situações extremamente fantásticas. Os autores do livro optaram por inserir uma foto extraída do filme e ao lado abriram uma caixa de diálogo na qual podemos ler:

Você já assistiu a algum filme em que o personagem central da trama fosse um arqueólogo? O cineasta Steven Spielberg criou o personagem Indiana Jones (ver foto abaixo), que realiza expedições arqueológicas. Ele foi protagonista de quatro filmes do diretor. Por ser um filme de ficção, feito para divertir, as histórias vividas pelo personagem não fazem parte do cotidiano de um arqueólogo: são cheias de aventuras impossíveis (CABRINI et al., 2010, 6º ano, p. 89).

Por parte dos autores há uma preocupação em prevenir os usuários do livro a respeito das possíveis invenções ou exageros históricos propagados, eventualmente, pelo cinema. Além disso, também fica evidente a ideia de que, ao contrário do que evidencia o filme de Spielberg, a história não é repleta de fantasias, tampouco a rotina de trabalho de um arqueólogo. 
No capítulo intitulado "Diferenças entre seres humanos e outros animais", há a explicação, por meio de exemplos, de como seres humanos podem adquirir hábitos comportamentais referentes a outras espécies, devido à convivência. Apesar disso, características humanas, como a racionalidade, definirão suas diferenças. Para tanto, a figura de Tarzan é invocada por meio de uma fotografia extraída do filme $O$ tesouro secreto de Tarzan (1941). A legenda da foto contém a seguinte informação: "Tarzan foi representado várias vezes no cinema”. A partir dessa imagem extraída do filme, cujo protagonista era o nadador Johnny Weissmuller, há a proposta de atividades com o intuito de promover maior compreensão do tema. A questão proposta referente ao filme é: "após observar a imagem, descreva o personagem Tarzan". Neste caso, assim como no caso do cartaz do filme Jeca Tatu, as imagens são usadas como uma fotografia, com o objetivo de ilustrar os dois personagens: o Tarzan e o Jeca. Isso ocorre por se tratar de filmes muito antigos, aos quais dificilmente alunos do ensino fundamental teriam assistido. Diferente da situação posta com os cartazes do filme do Homem-Aranha e de Indiana Jones, pois são tramas mais recentes, cujo público-alvo seria composto por jovens que, possivelmente, os conheceriam.

Apesar de os filmes não aparecerem com muita frequência nessa coleção, percebe-se que, eventualmente, os autores recorrem a esses para ilustrar uma temática, ou no sentido de acionar as memórias dos alunos, apresentando filmes que eles podem, em algum momento, já ter assistido. Ambas as estratégias representam meios de promover o ensino de História, mesmo que, no caso específico dessa coleção, os documentos audiovisuais tenham sido preteridos por outras formas mais tradicionais de documentos, basicamente escritos.

\section{Projeto Araribá}

O Projeto Araribá é uma coleção de livros didáticos editados pela Editora Moderna. Logo na abertura de todos os quatro livros do ensino fundamental II, a coleção é descrita como uma obra coletiva, contando com 11 autores listados na contracapa dos livros. Trata-se de obra cujo enfoque é a História Temática, e, em sua apresentação, há a descrição da subdivisão em duas partes que acompanhará todos os volumes da coleção: "Estudo dos Temas" e "Seção em Foco".

Nesta coleção, a indicação de filmes não ocorre de maneira uniforme, e no livro do sexto ano aparecem apenas cinco ocorrências. Em todos os casos as imagens capturadas dos filmes funcionam como fotografias com o intuito de ilustrar as caixas de texto que acompanham. Exemplo disso seria a aparição de uma imagem retirada do filme A Era do Gelo (2001) que busca emoldurar o texto a respeito da Era glacial. 
No livro do sétimo ano as referências ao cinema surgem em duas ocasiões: uma delas na página dez, com as imagens representando cavaleiros medievais em filmes com temas dos mais diversos. O ogro Shrek (2001), As crônicas de Nárnia (2005) e Star wars (1977) são apontados como exemplos de representações contemporâneas do mito do cavaleiro medieval cunhado por meio de romances como Tristão e Isolda e Ivanhoé. A comparação deve-se ao fato de que nesses filmes, assim como nos livros dos cavaleiros, sempre há a luta do bem contra o mal, ficando os representantes do bem marcados pela bravura e pela honestidade.

A segunda ocorrência de filme, nesse livro, é de $O$ nome da rosa, baseado em obra de Umberto Eco. Aqui o longa aparece em uma caixa de texto própria para a indicação de filme, diferentemente das outras encontradas no livro do sexto ano. Nesse caso, a imagem extraída do filme não vem para ilustrar o texto, mas surge como fonte de pesquisa para o aprofundamento do conteúdo administrado.

As ocorrências mais relevantes de filmes na coleção Araribá História aparecem no livro do nono ano. Neste há uma diferença grande em relação aos outros livros da série, pois a seção intitulada "Filme", contendo indicação de filmes a respeitodos temas abordados nas caixas de texto, aparece em quase todos os capítulos. A unidade 1, intitulada "A Era do Imperialismo", conta com um subcapítulo que trata da Arte Moderna, e o cinema ganha destaque para explicar o início do século XX. O texto aponta o cinema como uma "arte para multidões", e mostra exemplos de sucesso nos primórdios de sua indústria, como Rudolph Valentino e Charles Chaplin. A diferença em relação ao cinema nessa unidade é que deixa de ser uma ferramenta de ensino para tornar-se conteúdo de aula. Essa indicação está em consonância com as diretrizes dos PCNs, conforme vimos anteriormente, pois propõe a investigação dos primórdios da indústria cinematográfica como forma de compreensão da dinamização da História do início do século XX.

No decorrer dos capítulos, conforme já dito, a seção "Filme" aparece sugerindo filmes comerciais, mas também outros que fogem desse circuito, como A classe operária vai ao Paraíso (1971), do italiano Elio Petri, Glória feita de sangue (1957), de Stanley Kubrick, e Reds (1981), de Warren Beatty. Esses são exemplos que não foram citados pelos sete professores entrevistados como aqueles escolhidos para serem trabalhados em aula (PEREIRA, 2013), o que ressalta a possibilidade de não serem conhecidos não somente pelos alunos, mas também pelos professores.

Na unidade 3, dedicada ao estudo do nazismo, há a indicação de que o cinema havia sido usado pelo regime ditatorial do Terceiro Reich a fim de disseminar suas ideias junto à população. $\mathrm{O}$ cartaz do filme, hoje proibido na Alemanha, intitulado "O judeu Süs", de 1940, aparece como forma de ilustrar o tópico "Arianismo e antissemitismo". Além desse filme, outros tantos referentes a Segunda Guerra Mundial 
são apresentados nesse capítulo: os filmes Julia (1977) e Uma mulher contra Hitler (2005) são citados acompanhando textos relacionados à resistência; já o cartaz do "blockbuster" Pearl Harbor" (2001) acompanha a questão de vestibular sobre o evento retratado no filme, para que os estudantes testem seus conhecimentos a respeito do conteúdo. O cartaz do filme brasileiro Olga (2004) acompanha um texto relacionado à militante comunista, propondo atividades de pesquisa de sua vinda para o Brasil e sua participação na Intentona Comunista.

No fechamento do conteúdo que dizia respeito à Segunda Guerra, o livro traz atividade baseada em cartazes do filme Olympia (1938) e de propaganda elaborada pelo Departamento de Imprensa e Propaganda (DIP).

$\mathrm{Na}$ atividade sugerida pelo livro, há a análise das imagens, o estudo do contexto no qual cada uma dessas emergiu e, por fim, a última questão refere-se às semelhanças existentes entre um cartaz e outro. Nesse ponto, o livro sugere identificações em relação ao uso da propaganda como forma de divulgação de duas teorias políticas diferentes (porém, com certas semelhanças), o nazismo na Alemanha e o Estado Novo no Brasil. A análise dessas duas construções visuais possibilita que o aluno transcenda a simples leitura da imagem e aprofunde seus conhecimentos, buscando saber de que maneiras esses recursos visuais serviram e servem a interesses políticos de toda ordem.

Diferentemente da coleção História Temática, a Araribá busca no cinema uma fonte frequente de abordagem histórica. $O$ fato de haver seções específicas para indicação de filmes aponta para uma importância dada ao cinema que não se encontra na História Temática.

\section{Considerações finais}

As questões pontuadas nesses documentos trazem uma provocação sempre tão indispensável à concretização dos processos de ensino: seria possível verificar em livros, cujos títulos evocam a premissa básica da prescrição uma receita de como deve-se ensinar História? E nos PCNs, encontraríamos tal força?

Muito mais importante do que identificar as receitas, sugestões, conselhos, métodos defendidos por diferentes autores seria compreender de que maneira o ensino de História era pensado nos períodos em que foram escritos o livro de Serrano, os PCNs, o livro de Napolitano e os livros didáticos das coleções História Temática e Araribá.

Em obras diferentes, escritas em períodos e por autores igualmente diferentes, o que se percebe é uma preocupação muito intensacom os rumos tomados pelo ensino de História, preocupação também evidente nos Parâmetros Curriculares Nacionais. Como deveria ser ensinada a História talvez tenha sido a maior preocupação nos documentos analisados, não necessariamente como essa é aprendida. 
Compreende-se que mais importante do que a prescrição é a prática, mas como ignorar a existência de tantas obras indicativas de uso e dos PCNs para o ensino de História, em épocas diferentes?

A Associação do cinema ao ensino de História mudou com o tempo, assim como as indicações feitas para isso. Perceber as mudanças que ocorreram para a construção desse tipo de manual no tempo pode servir-nos e muito para analisar quais heranças daqueles pontos de vista ainda sobrevivem nas práticas desempenhadas por professores na contemporaneidade.

Sabe-se que a prescrição tem por premissa a contribuição para a construção da prática e que esta também pode interferir no que é prescrito, uma vez que o texto dos Parâmetros e todos os livros analisados são resultado da inquietação de seus autores, professores de ofício.

Buscou-se aqui apontar, por meio da análise de manuais e livrosdidáticos de ensino de História, as diferentes possibilidades de mobilização do cinema para atividades em sala de aula, focadas na reflexão histórica. Alguns livros acompanham as indicações dos PCNs e utilizam da própria história da invenção do cinema como uma compreensão das construções sociais ao longo do tempo, entretanto, tais recomendações não são vistas em grande parte dos manuais didáticos.

Uma importante questão que deve ser ressaltada está na própria temporalidade que permeia a forma de uso dos filmes. Estes têm história, portanto o seu uso também registra suas continuidades e rupturas.

Saber analisar criticamente o filme visto em sala de aula contribui para que os discentes treinem seu olhar para os que vierem a assistir em casa ou no cinema. Essa preparação para decodificar as intenções, os objetivos e as entrelinhas existentes em cada filme acaba por potencializar o repertório de conhecimentos, conquistados pelos alunos, dentro e fora dos muros da escola. Para tanto, o olhar do docente (muitas vezes impregnado pelas indicações oriundas dos manuais didáticos) funciona como mediador dessas experiências, provocando a reflexão crítica ao conhecimento adquirido por meio do cinema.

\section{How to use film in the classroom? Notes and prescriptions for history teaching}

\section{Abstract}

This article presents an approach to the institutionalization of parameters to associate film with History teaching. The analysis was performed considering the collection of documents in common, namely prescriptive discourse related to the use of film in the classroom. Within that line, governmental parameters for the national curricula (Parâmetros Curriculares Nacionais - PCN) were analyzed, as well as two didactic textbook collections and two handbooks for History teachers, of 
different periods. The objective was to identify ruptures and eventual remains when exploring constitutive aspects of prescribing film use in a classroom environment. This discussion is part of a research study developed in the MA program of Universidade do Estado de Santa Catarina (Udesc) defended in 2013, in which a group of municipal middle-school History teachers used film in the classroom were studied. The issues brought to surface by this article are intended to contribute with the understanding of how prescription to use film in History teaching has changed with time, and the present status quo.

Keywords: History teaching and learning. Film. Prescription.

\section{Nota}

1 Disponível em: http://www.cinemateca.gov.br. Acesso: 12 fev. 2013.

\section{Referências}

A CLASSE Operária vai ao Paraíso. Diretor: Elio Petri. Itália: Euro, 1971. 1 DVD (125 min), preto e branco.

A ERA do Gelo. Diretor: Cris Wedge. EUA: Fox, 2001. (90 min), animação colorida.

APOLINÁRIO, Maria Raquel. Projeto Araribá. 3. ed. São Paulo: Moderna, 2010.

AS CRÔNICAS de Nárnia. Diretor: Andrew Adamsom. EUA: Disney, 2005. 1 DVD (135 min), colorido.

BITTENCOURT, Circe. Ensino de história: fundamentos e métodos. 1. ed São Paulo: Cortez, 2004.

BRASIL. Parâmetros Curriculares Nacionais. (5a 8ํㅗries). História. Brasília: MEC/SEF, 1998. Disponível em: <http://portal.mec.gov.br/seb/arquivos/pdf/pcn_5a8_historia.pdf>. Acesso em: 26 mar. 2014.

CABRINI, Conceição; CATELLI, Roberto \& MONTELLATO, Andrea. História temática: tempos e cultura, diversidade cultural e conflitos, terra e propriedade e $\mathrm{O}$ mundo dos cidadãos. 3. ed. São Paulo: Scipione, 2010.

FERRO, Marc. O filme: uma contra-análise da sociedade? In: LE GOFF, Jacques; NORA, Pierre. História. novos objetos. Rio de Janeiro: Francisco Alves, 1995. p. 199-215.

GLADIADOR. Diretor: Ridley Scott. EUA: Estúdios Universal, 2000. 1 DVD (154 min), colorido.

GLÓRIA Feita de Sangue. Diretor: Stanley Kubrick. EUA: Bryna, 1957. 1 DVD (88min), preto e branco.

HOBSBAWM, Eric. Sobre história. São Paulo: Cia das Letras, 1998.

HOMEM-Aranha. Diretor: Sam Raimi. EUA: Columbia, 2002. 1 DVD (121min), colorido.

INDIANA Jones e o Reino da Caveira de Cristal. Diretor: Steven Spielberg. EUA: Paramount, 2008. 1 DVD (122min) colorido. 
JECA Tatu. Diretor: Milton Amaral. Brasil: Unida Filmes, 1959. 1 DVD (95 min), preto e branco. JÚLIA. Diretor: Fred Zinnemann. EUA: Fox, 1977. 1 DVD (118 min), colorido.

LE GOFF, Jacques. História e memória. Campinas-SP: Ed. Unicamp, 2003.

LE GOFF, Jacques; NORA, Pierre. (Orgs.). História: novos objetos. Trad. Terezinha Marinho; Rev. téc. Gabriel Perruci. 2. ed. Rio de Janeiro: Francisco Alves, 1986.

LOURENÇO FILHO, Manuel. O ensino renovado e a história. Apresentação. In: SERRANO, Jonathas. Como se ensina história. São Paulo: Melhoramentos, 1935. p. 7-12.

MARIA Antonieta. Diretor: Sofia Coppola. EUA: Estúdios Columbia, 2007. 1 DVD (176 min), colorido.

MORETTIN, Eduardo Victório. Cinema educativo: uma abordagem histórica. Comunicação e Educação, São Paulo, v. 2, n. 4, p. 13- 19, set.-dez. 1995.

. O Cinema como fonte histórica na obra de Marc Ferro. História: Questões \& Debates, Curitiba, v. 1, n. 38, p. 11-42, jan.-jun. 2003.

NAPOLITANO, Marcos. Como usar o cinema em sala de aula. 4. ed. São Paulo: Contexto, 2009.

O JUDEU Süs. Diretor:Veit Harlan. Alemanha: Produtora?, 1940. 1 DVD (90 min), preto e branco.

O TESOURO Secreto de Tarzan. Diretor: Richard Thorpe. EUA: Warner, 1941. 1 DVD (91 min), preto e branco.

OLGA. Direção de Jaime Monjardim, Brasil: Globo, 2004. 1 DVD (141 min), colorido.

OLYMPIA. Diretor: Leni Riefensthal. Alemanha: Produtora de Olympia: UFA (Estatal Alemã de Cinema), 1938. 1 DVD (121 min), preto e branco.

PALMA FILHO, João Cardoso. Os Parâmetros Curriculares Nacionais. Nuances, Presidente Prudente, v. 3, n. 3, p. 15-19, set. 1997.

PEARL Harbor. Diretor: Michael Bay. EUA: Touchstone, 2001. 1 DVD (183 min), colorido.

PEREIRA, Lara Rodrigues. Entre prescrições e práticas: o cinema no ensino de História. 2013. Dissertação (Mestrado em História) - Programa de Pós-Graduação em História, Universidade do Estado de Santa Catarina, Florianópolis, 2013.

REDS. Direção de Warren Beatty. EUA: Fox, 1981. 1 DVD (195 min), colorido.

SERRANO, Jonathas. Como se ensina História. 1. ed. São Paulo: Melhoramentos, 1935.

SREK. Diretor: de Andrew Adamsom. EUA: Dreamworks, 2001. 1 DVD (90 min), colorido.

STAR Wars. Diretor: George Lucas. EUA: Fox, 1977. 1 DVD (121 min), colorido.

UMA Mulher Contra Hitler. Diretor: Marc Rothemund. Alemanha: Goldkind Filmproduktion, 2005. 1 DVD (117 min), colorido. 